\title{
Making with Shenzhen (Characteristics)—Strategy and Everyday Tactics in a City's Creative Turn
}

\author{
Siyu Chen ${ }^{1, *}$ and Jian Lin $^{2}$ \\ 1 Faculty of Humanities and Social Sciences, Harbin Institute of Technology (Shenzhen), \\ Shenzhen 518055, China \\ 2 Department of Media Studies and Journalism, University of Groningen, \\ 9712 EK Groningen, The Netherlands; j.lin@rug.nl \\ * Correspondence: chensiyu@hit.edu.cn
}

Citation: Chen, S.; Lin, J. Making with Shenzhen (Characteristics) Strategy and Everyday Tactics in a City's Creative Turn. Sustainability 2021, 13, 4923. https://doi.org/ $10.3390 /$ su13094923

Academic Editor: Kylie Peppler

Received: 23 February 2021

Accepted: 22 April 2021

Published: 28 April 2021

Publisher's Note: MDPI stays neutral with regard to jurisdictional claims in published maps and institutional affiliations.

Copyright: (c) 2021 by the authors. Licensee MDPI, Basel, Switzerland. This article is an open access article distributed under the terms and conditions of the Creative Commons Attribution (CC BY) license (https:// creativecommons.org/licenses/by/ $4.0 /)$.

\begin{abstract}
This paper investigates the government-led maker movement in Shenzhen, China by deploying Michel de Certeau's concepts of "strategy" and "tactics". While there is a growing body of literature surrounding the maker movement, the discrepancy between the maker movement presented in urban policies and its participants' actual practices is underexplored. Situating the exploration in the Chinese context, this article looks into how state intervention shapes the maker movement and actors' participation. This work starts with considerations of political economy to demonstrate how the "Make with Shenzhen" campaign as a strategy fits into the government's creative city agenda. It then draws upon the findings of a longitudinal ethnographic study to illuminate how discourses, institutions and apparatuses are tactically appropriated by individuals to mobilize symbolic, monetary, social and political resources to serve their interests. We argue that these tactical practices can potentially lead to meaningful changes in the city of Shenzhen and the everyday life of its people. By juxtaposing the strategy of the "Make with Shenzhen" campaign with the tactical practices surrounding it, this study offers insight into the challenges and possibilities brought about by the city-wide learning and making in the Chinese context.
\end{abstract}

Keywords: creative city; maker movement; urban regeneration policies; ethnography; China

\section{Introduction}

In 2015, maker culture in Shenzhen, China rose to prominence when the Chinese government issued a new national policy aimed at the promotion of "mass makerspaces", "mass entrepreneurship" and "mass innovation". This national initiative aims to dovetail grassroots creativity with pre-existing policy discourses of the creative city, creative industries and "Internet + ", in which culture, creativity and digital technologies are recognized as the new driving forces for urban and national economic growth [1]. Aspiring to become a global creative city, Shenzhen has taken a lead in this state-led maker movement by launching the "Make with Shenzhen" program in 2015. With the aim of encouraging the public to take part in building a creative Shenzhen, "Make with Shenzhen" is a campaign that provides funding and publicity support for the promotion of maker culture. Under the slogan of "Make with Shenzhen", in 2015 the city witnessed an explosion of makerspaces, with the number of makerspaces increasing from 4 to more than 200 within just one year [2].

The proliferation of makerspaces, together with dazzling technologies and the officially propagated myth that "everyone can be a maker", has kindled hope and passion for creativity and innovation among individuals from different backgrounds. However, this mass enthusiasm for entrepreneurial pursuits is underpinned by heavy governmental intervention. At present, some makerspaces have closed down, and the feeling that the makerspace bubble is deflating has led to confusion, doubt and introspection. Who are the makers, what do they learn to make in the government-led maker movement and how would city-wide learning and making shape the contours of the maker movement? 
We argue that a rethink of the "Make with Shenzhen" campaign can shed light on the challenges and opportunities of the maker movement in the Chinese context.

There is a growing body of literature surrounding the maker movement. Some laud the movement for its potential to initiate an "industrial revolution" [3], while others scrutinize its possible side effects, including intensified consumption [4], gender inequality [5] and labor exploitation [6]. More recently, this literature has focused on the promotion of the maker movement as a part of urban development policies. There have been studies exploring its planning dimension [7], its influence on local entrepreneurial activities [8], innovation ecosystems [9] and urban imaginaries [10]. In the Chinese context, the media hype and political frenzy surrounding the Chinese maker movement have led to an emerging scholarship, of which a series of studies conducted by Lindtner [11-14] were the first attempts. Drawing on the long-term ethnography of Chinese maker communities, her work convincingly demonstrates the relationship between technology use, production, activism and the Chinese party-state. Further, other scholars have investigated the political implications of the Chinese maker movement with a focus on topics such as space, participation and community [15-19]. As illuminating as these studies are, there has been little research conducted on the discrepancy between the maker movement as it is presented in urban policies and the reality of its participants' actual practices. Recent studies have shown that the evolving relationship between neoliberalism and state-led developmentalism in Asia leads to a sizable gap between urban policies and their materialization $[19,20]$. Particularly in the Chinese context where the market economy incorporates neoliberal elements with centralized control [21], how state intervention shapes the maker movement and actors' participation in the movement warrants an in-depth explication of its unique characteristics. Responding to Comunian's [22] call for a more agent-focused and interaction-based understanding of the development of creative cities, this study delves into the practices of and interactions between individual makers, real estate developers, funding agencies and urban government in the "Make with Shenzhen" campaign. Illuminating the way that diverse actors negotiate the meanings of makers, makerspaces and making in Shenzhen's creative turn, this study demonstrates the fluidity, multiplicity and interconnectedness of the maker movement in urban regeneration. By examining how the government-led campaign informs the citizenry of Shenzhen, and how the city-wide learning and making, in turn, lead to the changing contours of the maker movement in the Chinese context, this study further contributes insights to the relevant literature by exploring the power interplay between government, market forces and the public.

\section{Theoretical Framework and Methods}

This article draws upon Michel de Certeau's concepts of strategies and tactics. The official "Make with Shenzhen" campaign has been structured by the calculus of what de Certeau calls a "strategy". According to de Certeau [23] (p. xix), strategies "assume a place that can be circumscribed" which they then manage as they master the exteriority. Strategies prescribe what is desirable and form the "institutionalized frameworks, scripts, or patterns of action that serve as general guides to behaviour" [24] (p. 49). "Subjects of will and power" employ strategies, which consist of centralized and rationalized rules. Based on these rules, subjects assemble "objective" political, scientific and economic models [23] (p. xix). De Certeau offers some examples of such "subjects of will and power", including a business enterprise, an army, a scientific institution and, crucially here, a city. Particularly in the Chinese context where the nation-state continues to exert substantial influence over political and economic resources [25,26], a city performs as a strategic tool for "effecting state power" [23]. Designated to be "China's experimental site for economic reform and a nurturing ground of human resources" [27], Shenzhen is a city where strategies are implemented to cultivate a pioneering, innovative and enterprising citizenry. These strategies include zealous government endorsement of the maker movement, dazzling events, burgeoning makerspaces, further inclusion of STEM courses in primary and middle school curricula and a myriad of media reports on the legendary successes of local entrepreneurs. 
Collectively, these invoke the mythologized imaginary of a creative Shenzhen, which reconfigures citizens' sense of self and place through the maker culture.

Beneath this official discourse that strategizes the innovative and entrepreneurial landscape of Shenzhen, there exists a different mode of power, which can be termed "tactics". According to de Certeau [23], tactics are defined by the absence of a proper locus. Occupying the gaps or interstices of the strategic grid, tactics do not stand in opposition to strategies but "traverse" and "infiltrate" systems by playing out "the guileful ruses of different interests and desires" [28]. While the city serves as a totalizing and almost mythical landmark for socioeconomic and political strategies, urban life increasingly permits the re-emergence of elements that the urbanistic project excludes [23] (p. 95). Holding the promise of exciting newness and unlimited possibilities, the "Make with Shenzhen" campaign reaches out across physical and social distance to kindle public and individual aspirations. However, as the city is not a field of programmed and regulated operations [23] (p. 95), the desires fueled by it are diverse, fluctuating and, at times, contesting, leading to citizens' dispersed practices to serve their own interests. Opaque and quiet as they may be, these practices are capable of deflecting the imposing and dominating campaign of the maker movement in Shenzhen.

Treating the official campaign of "Make with Shenzhen" and its participants' actual social practices as two different conceptual entities, viz., strategies and tactics, this article explores not only how the "Make with Shenzhen" campaign is organized and implemented by the government, but also how these discourses, institutions and apparatuses are also tactically negotiated and appropriated by different actors to serve their own interests. Through the lens of the maker movement in Shenzhen, this study sheds light on the tactical practices of creative city discourses in a local urban context and the potential of these practices to change the city and its people.

As Smart [29] notes, ethnographic approaches are particularly useful for investigating the tensions between urban policies and people in China where a "regulatory vacuum" makes considerable room for negotiation and compromise. Following his advice, this study has adopted a multi-sited, longitudinal ethnographic approach to examine the diverse practices in the "Make with Shenzhen" campaign. The field study was conducted by Chen from July 2017 to October 2020. This methodological approach included hands-on participation in more than thirty online and offline maker-related events in Shenzhen, including Maker Faires, Entrepreneurship Contests, Start-up Weekends and Hackathons, etc., in addition to multiple visits to different makerspaces. Besides, rooted in and responsive to the experience of a particular social position, participants' personal insights into the "Make with Shenzhen" campaign shed light on how values and beliefs on the maker movement can be shaped by the political, economic, and sociocultural circumstances in society. Therefore, 72 semi-structured interviews were conducted with relevant stakeholders, including members, owners and operators of makerspaces, government officials, agencies, entrepreneurs and investors, and generally creative and entrepreneurial citizens. Informants were recruited by way of snowball sampling. With the consent of the informants, most of these research data, including 57 interviews, were documented through audio and video recording. Notes were taken during the interviews when interviewees chose not to be recorded, and reflective memos were completed afterwards to summarize major themes and personal impressions. Identifiable information was removed and pseudonyms were used for those who preferred not to be identified. The field data are complemented by an extensive collection of newspaper articles, policy documents and media texts that range from news reports, newsletters, and Facebook pages to WeChat public accounts. By looking at themes, contextual considerations, references, emphases, silences and variations, interview transcripts were coded and patterns were identified to underline and expose the complex, contextual and changing discursive practices surrounding the maker movement in Shenzhen. 


\section{Results: Field Findings}

In this section, we will first analyze the political economy of Shenzhen's maker movement, explicating the way that the "Make with Shenzhen" campaign as a strategy fits into the official agenda of the creative city and urban regeneration. Based on data collected through extensive field studies, we then demonstrate how the "Make with Shenzhen" campaign has led to the changing definition and composition of "makers", how the tactical appropriation of the campaign through the interactions of different actors has given birth to "makerspaces" in multifarious forms, and finally how these emerging physical and social spaces open up new possibilities of "making" that can potentially bring about changes to the city and its people.

\section{1. "Make with Shenzhen" as a Strategy}

Since its designation as China's first Special Economic Zone in 1979, Shenzhen has risen from a small border town with a population of around 20,000 and a GDP of USD 27.4 million in 1979 to a megacity with around 20 million residents and a GDP of USD 335.7 billion in 2018 [30]. Despite its phenomenal growth, Shenzhen faces multiple challenges to maintain its economic development. Its economic success heavily relies upon foreign investment-led and labor-intensive manufacturing industries. Its rising labor costs and land prices induce fierce competition both at home and abroad, which has been further intensified since the global economic recession of 2008. Moreover, Shenzhen is a migrant city, and its lack of a strong cultural identity may potentially lead to a weak level of commitment by more skilled and educated professionals, which could be a roadblock to the city achieving sustainable growth and prosperity [31].

To tackle these problems, the Shenzhen Municipal Government issued the Shenzhen Declaration in 2004, in which 94 cultural and creative sectors were included in its 11th five-year plan for economic and social development. Since then, various schemes, such as the use of government subsidies and incentives, tax exemptions and governmentsponsored social events, have led to the rapid growth of the creative industries in Shenzhen. In the 2010s, technological innovation and entrepreneurship were further included in Shenzhen's creative city planning. In the Shenzhen Cultural and Creative Industries Revitalization and Development Plan 2011-2015, technology, finance and tourism sectors were incorporated into the city's cultural industries to create a "new economic development model" [32]. In 2014, Shenzhen was designated as the first city-based National Independent Innovation Demonstration Zone, signifying its status as the national model in scientific and technological innovation.

This strategic focus on technological innovation and entrepreneurship has to do with Shenzhen's industrial heritage and the burgeoning grassroots maker culture that has stemmed from it. At times, Shenzhen has served as the manufacturing center for the global information technology industries [13]. Operating through an informal network and a culture of sharing, the dense web of manufacturers in Shenzhen caters to less well-known or no-name clients interested in producing smaller quantities of goods [13]. This informal manufacturing ecosystem, known as shanzhai in Chinese, demonstrates an interesting convergence and resonance with the founding spirit of the maker culture-grassroots, opensourced and entrepreneurial. Comprised of a complete supply chain of producers, traders, design solution houses, vendors and assembly lines, Shenzhen's shanzhai ecosystem has made the city an ideal place for makers to produce affordable and increasingly advanced electronics. As a global epicenter of hardware, Shenzhen stepped into the spotlight at a time of overriding national policy interests in innovation and entrepreneurship.

On 4 January 2015, during his inspection tour of Shenzhen, Premier Li Keqiang paid a visit to Chanhuo Makerspace. Lauding grassroots creativity as an enduring engine of China's economic growth, Li's talk signaled a watershed moment in state innovation policy, which embodies the national pursuit of rebranding China as a creative nation where every citizen should participate in the revolution from "made in China" to "created in China" [16] (p. 47). A few weeks after Li's visit, the State Council issued a new national policy on 
"Mass Entrepreneurship and Innovation" to support the creation of mass makerspaces and the proliferation of a maker approach to the nation as a whole. According to the minister of science and technology Wan Gang [33], the government endorsement of the maker movement is a means to "adapt to the 'new normal' in China's economic transformation" and "an opportunity for everyone to realize a lifelong dream, including the underprivileged youth". Wan's remark, as Lindtner and Avle [34] note, referenced two inter-related phrases that prevail in Chinese political discourse: "China's new normal" and the "Chinese dream".

First used by President Xi Jinping in May 2014 when describing changes in China's social, economic and political conditions, China's "new normal" is characterized by the slowdown of growth and the process of upgrading the country's economic structure. Faced with an increase in wealth inequality, financial instability and industrial overcapacity, structural changes in the economy have brought about an increasingly volatile labor market and precarious labor conditions [35]. Under such circumstances, the "Mass Entrepreneurship and Innovation" campaign is an ad hoc solution for China's economic transitional crisis [26,34]. During the time of China's "new normal", the government seeks to build a normative consensus and shared identity by promoting the aspirational slogan of the "Chinese dream" [36,37]. Initiated by President Xi shortly after he took office in 2012, the national discourse of the "Chinese dream", or what Xi defined as "the great rejuvenation of the Chinese nation", is an act of moral and political leadership that seeks to resonate with Chinese citizens by emphasizing the opportunity for all Chinese to achieve prosperity [37]. This form of governance articulates with the state's growing commitment to the advancement of science and technology [1], leading to the officially propagated maker movement that engages Chinese society in the visions and enactments of multiple technological, economic and social futures for China [12,34]. In the national project of Mass Entrepreneurship and Innovation, Shenzhen stands as a privileged locale to experiment with making on a mass scale. For one thing, the challenges Shenzhen is facing-including the shift to a knowledge-based economy, intensified competition and the absence of a collective identity in an increasingly heterogeneous and stratified society-epitomize China's plight in the era of the "new normal" of the "Chinese dream". Furthermore, as mentioned earlier, the shanzhai ecosystem in Shenzhen has turned out to be a treasure trove for makers, which has made the city a prime site for examining the possibilities and limits of a "maker approach" to the transformation from "made in China" to "created in China". Just one day after Premier Li's visit to Chaihuo, the Shenzhen-San Francisco International Exchange on Open Innovation was hosted by the Shenzhen government in San Francisco. Having drawn more than 300 international makers and industry insiders, this event was the debut of the "Make with Shenzhen" campaign to promote the city's makers along with an innovative ecosystem worldwide. In addition, the Shenzhen government launched a three-year action plan to have the city host 200 makerspaces by the end of 2017 (an annual increase of 50 makerspaces per year) [37]. CNY 2 billion was allocated for this plan, which provided up to CNY 5 million per site for new makerspaces, the expansion of existing makerspaces or the introduction of overseas makerspaces to Shenzhen [38]. Moreover, the city has been actively building a reputation as a hub of innovation education at all levels, from kids education clubs, to junior academies of science for teenagers, to incubators and accelerators for emerging designers and engineers. The Shenzhen municipal government has also issued policies to promote the maker movement among college students; these measures have included legitimating students' academic leave so they can pursue entrepreneurial work, providing subsidies and loans, offering favorable tax treatment and free advisory services, etc. [39].

\subsection{Tactical Practices in "Make with Shenzhen"}

This enthusiastic political endorsement and generous funding, together with the widely promulgated belief that "everyone can be a maker", have sparked individual ambition in maker entrepreneurship. The massive participation in and mobilization of the "Make with Shenzhen" campaign among different interest groups, as we will show in the 
following sections, have led to fluid and contested meanings of "maker", "makerspace" and "making".

\subsubsection{A Multitude of Makers}

"Honestly, I don't know what it exactly means", Mr. Hu, a makerspace operator, said while looking somewhat perplexed when asked about the definition of a "maker" (chuangke). Hu's confusion has to do with the fuzzy meaning of "maker" in the Chinese context. Originated in the San Francisco Bay Area by technological hobbyists in the mid2000s, the maker movement was initiated by a group of Do It Yourself (DIY) enthusiasts who shared a passion for digital fabrication. The maker movement in China began in the early 2010s. During the planning stages of the first international maker carnival in Beijing in 2012, China's makers settled on an alternative term: chuangke (creative professional) [11]. With the advantage of connoting both creativity (chuangyi) and innovation (chuangxin), chuangke is employed as a positive term within the wider creativity discourse [11]. Incorporated into the state's much-touted policy goal of "Mass Innovation and Entrepreneurship", the concept of "maker" has received unprecedented media hype and public attention, ranked first in the top 10 Chinese internet buzzwords of the first half of 2015 [40]. While the Chinese government encourages everyone to explore their creativity, risk-taking and play [41], this approach focuses more on bringing out its entrepreneurial potential rather than promoting the "organic" maker spirit that, according to Dale Dougherty [42] (p. 12), "celebrates cooperation, creative freedom and hands-on experience".

Moreover, generous government sponsorship further complicates the composition of makers. The Shenzhen Municipal Government, as mentioned earlier, has released a funding policy for makers that provides up to CNY 500,000 (USD 74,130) to each maker or maker project [39]. This enthusiastic support from the authorities has motivated thousands of Chinese individuals from diverse backgrounds to become "makers", and Chinese makerspaces have been flooded with new faces, many of whom have little or no experience, expertise or genuine interest in creating. The potential financial benefit has even given rise to a service that helps makers prepare the application to receive these grants from the government. While some makerspaces hire consultants to update their members about the latest favorable policies, independent intermediaries can earn commission by providing services such as writing proposals, packaging application materials, liaising with government officials, and assisting with project inspection if the application is successful. "I feel the fund for makers is pretty much like the pension program in the West," an intermediary commented, "it is especially tempting to those who are unemployed and need some initial capital to start their business, and we are there to facilitate the process."

Encompassing opportunists, amateur hobbyists and professional entrepreneurs, the term "maker" has become increasingly ambiguous in this government-sponsored maker movement, which opens possibilities for individuals' tactical self-representation. Like many informants, Zhao, the inventor of a large-scale irrigator, was in the process of applying for the much-coveted Shenzhen Municipal maker fund at the time of our interview. However, he refused to identify as a maker:

"I am a hardcore geek, not a maker who makes stuff out of some whimsical ideas. I love technical stuff, and I used to be a member of a hardware interest group for years. As for this project, my partner and I have been working on it for three years, and we are confident that this is the best solution with superb effectiveness in terms of both cost and function."

Fang, who obtained his master's degree in artificial intelligence in France, was the recipient of a grant for his project on intelligent robots. He also challenged the appellation of "a maker" by stating:

"I am not a maker but an entrepreneur. Makers are amateurs, they lack technical expertise and business acumen. They more than often overlook the market needs, and their products are usually immature. Running a start-up is a sophisticated job for elites, not for some random unemployed college graduates." 
Like Zhao and Fang, many technology-related professionals, while tactically seeking to include themselves in maker-related policies, emphasize their dedication, expertise, experiences and professionalism to distance themselves from makers that, as the Chinese government claims, "anyone can be".

While some resist the "plebification" of innovation and entrepreneurship that is promoted by the official maker movement, others embrace the label of a "maker" because of its connotation of creativity. Mr. Li, a furniture dealer who sells his merchandise online, rented a desk at a makerspace. While the seemingly uncreative trading business might render him a misfit in the "creative" workplace, Mr. Li nevertheless saw himself as a maker. "I am experimenting with new business models with the aid of the internet", Mr. Li claimed, "I am as creative as any other maker". Similarly, Kathy, an artist at the Dafen oil painting village, called herself a "cultural maker" to distinguish her original paintings from the replicas that were prevalent in Dafen. Like Mr. Li and Kathy, many of those who work outside of the technology domain that is commonly celebrated by maker-related policies identify as "makers". As the creative economy endorses the superiority of creative labor over other forms of labor [43] (p. 66), individuals tactically mobilize its symbolic resources to establish a sense of creative identity that for many is seen to justify their access to makerspaces - a term that, as will be demonstrated in the next section, has become increasingly equivocal in the daily practices of Shenzhen's maker movement.

\subsubsection{Contested Makerspaces}

In 2015, Henk, a Dutch entrepreneur, joined his expat friends for a three-day makerspace tour to look for a place to continue his hobby of making in Shenzhen. Having failed in his search, he ended up founding his own makerspace, Trouble Maker, in the following year. Recalling the makerspace tour, he commented:

"It struck me that most of the makerspaces here were very different from what one would expect. Very few of them provided labs. Those which were with labs offered little guidance, and the use of tools was strictly regulated. It seemed that they just wanted to keep their places tidy and clean ... and most of the large makerspaces were owned by real estate developers, and they operated on rent instead of [on a] membership basis".

Henk's observations are acute. Positioned as accelerators for creative and technologyled innovation, makerspaces had been increasingly in the spotlight since Premier Li's visit to Chaihuo [18]. As part of the "Make with Shenzhen" Campaign, the local government has enthusiastically supported the founding and operation of makerspaces. Similar to Luo and Chan's [26] observations of the production of China's coworking spaces, strong state intervention in the form of diverse subsidies, awards and mega projects distinguishes the provision of these spaces from their Western counterparts. Legions of dubiously named makerspaces have been built to take advantage of this governmental support. As a result, "makerspaces" have become contested physical and social spaces created and mobilized by individuals and organizations with diverse and even conflicting interests. The transformation of WeHome, an apartment building in Shenzhen, is a case in point.

Located in a former industrial area, WeHome is a chic apartment building converted from an old factory. While the bottom two floors serve as a co-working space for design and fashion start-ups, the top three floors are a co-living space made up of small units. With modern interiors, including a 100-metre graffiti-emblazoned lounge bar, a boutique café, a sleek yoga studio, a well-lit reading room and a brushed silver and grey kitchen, the WeHome complex houses around 160 tenants, most in their 20-30s, well-educated and well-paid. WeHome's transition into a makerspace began with the slogan on the entrance hall being changed from "Sweet home WeHome" to "Enjoy your creative life in your sweet home WeHome". The subdistrict office organized weekly training and workshops on entrepreneurship that took place in the lounge, where the graffiti on the walls was replaced by national flags and banners promoting the "Make with Shenzhen" campaign. While these events were often held during work hours when most of the tenants were not available, the organizers managed to use small gifts to attract dozens of audience members 
from the neighborhood, most of whom were retirees. Mr. Deng, the owner of WeHome, admitted that he is building a rather unconventional makerspace for "compelling reasons". In a move to cool down the sizzling property market, the government has encouraged the development of the leasing market. To win a bid for land parcels, bidding developers have to meet the new land sale rules that require buyers to keep a certain proportion of the developments on any given site available for rental and not sale purposes. In order to win the land during the bidding process and have a foothold in "China's hardware Silicon Valley", Mr. Deng pledged 100\% of his property for rental. Having to shift from a "build to sell" to a "build to rent" model, Mr. Deng struggles to sustain his project with limited revenue. He saw the governmental funds available for makerspaces as a way to make WeHome lucrative. The result is that Mr. Deng has been co-opted by the subdistrict office, which was looking for a venue to promote the "Make with Shenzhen" campaign. Similar to WeHome, many real-estate companies attempt to access funding by labeling themselves as makerspaces. In 2015, the number of makerspaces in China rose from around 70 to 16,000 [44]. However, as Henk's comments in the section above indicate, many of these lack adequate facilities to support real "maker" practice. According to Nesta [17], only a small portion of spaces in China can be truly identified as makerspaces, while the rest are disingenuously labeled as "makerspaces" for other purposes.

This sudden surge in "makerspaces" has also led to intensified competition. Signs of the bubble bursting started to show in early 2016 when quite a few makerspaces closed, including Peacock Organization, the winner of China's Top Ten Best Makerspaces Incubators contest in 2015. In 2016, around 55 percent of makerspaces were experiencing financial loss, and the average occupancy rate of makerspaces was 30 percent-well below the 60 percent many makerspaces need to break even [45]. This competitive market results in entangled practices, making makerspaces a site of contestation where the original ethos of technical innovation and openness is intermingled with, if not compromised by, other motives. The cases of Litchee Lab and 3W Coffice described below illustrate the attempts that different makerspaces make to straddle the contradiction between financial sustainability and public interest.

Litchee Lab, founded in 2014 at the location of a deserted canteen, was one of the very first makerspaces in Shenzhen. With an aim to promote DIY culture in the local community, the original Litchee Lab prioritized affordable access to analogue and digital design and aimed to provide facilities and space for both adult and teenage makers. Whereas adults paid a monthly fee of CNY 700 for 24/7 access to Litchee's equipment, students could enroll in training programs and workshops to study maker skills. The vibrant and collaborative vibe of Litchee Lab made it one of the international maker community's preferred makerspaces in Shenzhen, and it has been widely covered by international media publications such as Wired, Make Magazine and Forbes. Despite its rising global reputation, Litchee Lab found it hard to maintain focus on both its membership system and its educational programs and had to make up the financial losses of the former through the latter. Since 2017, it has concentrated on STEM education by offering paid courses and training. This transformation has helped Litchee Lab survive the "makerspace winter". Meanwhile, these readjustments, according to its founder Lit Liao, have also changed the nature of Litchee Lab:

"What matters about makerspaces is their open and sharing atmosphere. Litchee Lab used to be open to anyone, but at this stage, we've decided to focus on providing STEM education to school-aged children. We are transforming Litchee Lab into a STEM service provider."

Similar to Litchee Lab, some internationally recognized makerspaces in Shenzhen have to limit their membership and focus on providing value-added services to sustain themselves. Makerspaces relying primarily on rental income aim to boost their revenues by being all-inclusive, which paradoxically makes them fit into Lit's definition of a makerspace. Renting out each desk for CNY 800 to CNY 1500 (115-216 USD) per month without a membership requirement for eligibility, these makerspaces provide small-scale start- 
ups and entrepreneurial individuals with a low-threshold doorway into the makerspace communities. 3W Coffice is a case in point. Located at Shenzhen Bay Start-up Plaza, 3W Coffice hosts a diverse group of companies and start-ups at various life stages. Like many other "unorthodox" makerspaces in China, $3 \mathrm{~W}$ Coffice does not provide technical facilities, and it mainly relies on office rental fees to remain solvent. The frequent and dynamic social events it organizes make it popular; these include lectures, meetings and training. The group also actively promotes networking events and informal exchange between members at events such as happy hours, meetups and cocktail parties. "We welcome anyone who wants to rent a desk here", the business manager of 3W Coffice said, "Everyone has the potential to make, and they can always find a way to make". The affordable rent and communal atmosphere at $3 \mathrm{~W}$ Coffice open opportunities for those who are eager to make, although what they make may be distant from the original purpose of the government's campaign, as is shown in the following section.

\subsubsection{Making with Different Ends}

Jenny joined 3W Coffice without a team or a plan for what to make. As a "one-man band", she nevertheless did not keep a low profile at her office desk. With a fragrance diffuser, a vintage box for cosmetics and several cartoon figurines, Jenny's desk looked distinctively feminine. On the wall opposite her desk hung two images, a wall of screens displaying Nasdaq stock quotes and a family portrait of four. "These are magazine photos that I've collected", Jenny explained, "and they represent my life dreams-to have my company go IPO and to find a husband and have two babies." While starting a family might be easier than launching an IPO, Jenny found that in her previous job she did not have the time to look for a boyfriend. She previously worked as a software engineer at a Chinese transnational telecommunication company. The company's infamous "9-9-6" work culture, which expected employees to be in the office from 9 a.m. to 9 p.m., six days a week, together with the mundane and repetitive nature of the work, left her exhausted and frustrated. Finally, she quit her job and joined 3W Coffice in hope of starting her own business. When asked about her experience at $3 \mathrm{~W}$ Coffice, Jenny said:

"The members of the $3 \mathrm{~W}$ community have shared a lot of their thoughts and experiences with me, and I love the feeling of meeting new people and learning new things. I haven't made a business plan yet, but at least I am making a lifestyle change for myself."

Similar to Jenny, many informants joined makerspaces in Shenzhen to make changes. in their lives more than to make things; these changes might include "making more money", "working for myself", "having more free time", "meeting more likeminded people", or "exploring new possibilities in life". Most of these people were in their 20s and 30s, welleducated and at least temporarily with a certain degree of economic security. The economic slowdown in recent years has resulted in increasing layoffs and excessive overtime in the tech sector [46]. While recent graduates struggle to find a satisfying job in the shrinking labor market, more experienced employees aspire to achieve a desirable life-work balance and the experience of self-realization. Coinciding with the rise of post-Mao professionals who, as Hoffman [47] points out, embrace a "self-enterprising ethos", the government's promotion of the maker movement as "an opportunity to realize a lifelong dream" speaks to a cohort who hope to break free of a grueling and exploitative employment environment. With the potential to provide more freedom, power and reward, being an entrepreneurial maker appeals to these middle-class aspirants as "a line of flight" to distance themselves from their previous grueling work conditions and the routine and boredom with which they associate those environments [48]. Not all of these entrepreneurial aspirants are eligible for government funding, and most are aware of the precarity and insecurity that can accompany self-employment. They nevertheless regard this risky stance as worth taking because of the hope that getting involved with the maker community will bring knowledge and resources that will allow for an alternative way of life that transcends the mundane nature of daily routine. As Monique Bolli [49] (p. 73) succinctly points out, the 
autonomy of makerspaces is purposefully generated to enable people to choose what to learn, how and when.

For some of these young entrepreneurial aspirants, the changes they wanted to make were not only about their own lives but also about the larger society. Ni used to work as a business development manager at a makerspace, through which she developed an interest in the concept of "Business for Good". She commented:

"I've seen many people come to Shenzhen to start their business. The lucky ones managed to increase the valuation of their start-ups, got acquired and left, while others are still hanging on. For many of them, Shenzhen is just a transient hub, and they are too busy to get to know the city, let alone to do anything to make it better."

Aspiring to make "real change" in society, Ni nevertheless regarded her work at the makerspace as a necessary step to acquire entrepreneurial acumen and build networks to fulfil her ambition. In 2018, she left the makerspace and joined a social enterprise. The connections she built with the government and a design firm while working at the makerspace led to a government-funded joint project that aims to promote public awareness of issues of environmental protection through a gamified tour. "We are not building a unicorn, but we are definitely making changes to the city", said Ni proudly. Ni was among an emerging group that I encountered in Shenzhen who identified as "change-makers". Most were in their twenties or early thirties, with solid educational backgrounds and work experience. Different from the older generation of Chinese philanthropists who prized themselves on tackling social problems by taking an anti-entrepreneurial approach, this younger generation, nurtured under state innovation policies, takes a different approach to producing social good that blends the visionary and the practical [16]. Since social innovation in China is heavily intertwined with changes in government regulation and politics, social entrepreneurs need to work strategically within the system (Zhao, 2012) [49]. By tactically constructing "making change" as an alternative proposal to the ruling paradigm of "making enterprises", these media-savvy, entrepreneurial change-makers align themselves with the maker movement in Shenzhen as a way to mobilize political, economic and social resources for social innovation in China.

Empowering individuals through innovative learning and independent thinking, "making" is often understood to have a psychologically transformative and liberating potential (Breaux, 2017) [50]. While the democratic promise of "making" in the Chinese context is carefully channeled into economic discourses regarding the need to boost employment amid downward economic pressure, some individuals, as we have illustrated, have also attempted and managed to make changes, either for themselves or for the city. Their everyday practice generates new meanings of "making" that are different from its officially designated meaning.

\section{Discussion and Conclusions}

In 2017, right before the opening of the Mass Innovation and Entrepreneurship Week, a poster appeared on a pillar at the Shenzhen Bay Software Industrial Base Square. The poster read "Follow our party, start your business." Not far away was a piece of artwork that showed two faces: one defiant and one compliant (see Figure 1).

The accidental juxtaposition of the government slogan and the art piece epitomizes the interaction between the "Make with Shenzhen" campaign and the diverse, contested, and often seemingly self-contradictory practices of the actors involved with it.

In its agenda of economic restructuring through individual creativity and technological innovation, the Shenzhen government has enthusiastically promoted the "Make with Shenzhen" campaign. Generous political and financial support as part of the "strategy" has attracted a diverse group of individuals, including tech-savvies, investors, real-estate developers, social entrepreneurs and aspiring youth, each attempting to tactically mobilize symbolic, monetary, social and political resources to serve their own interests. The "Make with Shenzhen" campaign and its participants rely on mutual appropriation to sustain their operations. This process of interaction has provided opportunities for the practices of 
ordinary people to exercise a tactical effect on the official program. As de Certeau points out, a tactic artfully poaches and diverts the space where its practitioner is constrained by the existing order and institutions, and its success depends on its users' creativity, and most importantly, their ability to catch fleeting opportunities [23]. As shown in the preceding sections, the tactical effect of the participants' practices lies not on the fact that they openly challenge the official program, but on the fact that they run a course of their own that meets the needs of its practitioners. Through the creative negotiation of the meanings of "makers", "maker spaces" and "making", the campaign has been turned into a chance for budding entrepreneurs to garner financial support for their start-ups, for real-estate developers to generate more revenue under the tight rules regarding commercial vs. residential land use, and for aspiring individuals to learn from and connect with the entrepreneurial community. Articulating diverse power-related interests, the evolving maker movement in Shenzhen exemplifies how urban policies can be negotiated and mobilized by different actors through the interaction between official strategies and non-official tactics.

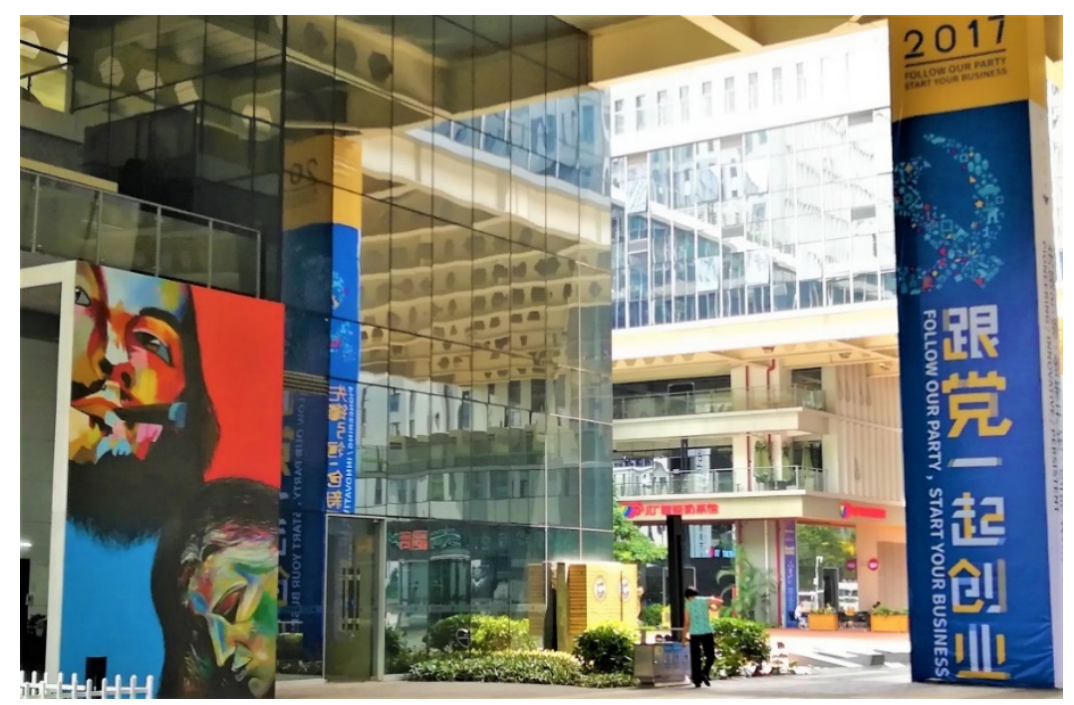

Figure 1. Shenzhen Bay during the Mass Innovation and Entrepreneurship Week, 2017 (Photo credit to Hu Bumin).

In the "Make with Shenzhen" campaign, where the rhetoric of creative disruption and neoliberal entrepreneurialism is underpinned by intense government intervention, tactical practices have connected the maker movement with public actions and private territories of capital accumulation to maneuver and divert the official strategy of urban regeneration and economic restructuring. The practices of the participants constituted "a hidden production" [23] of meaningful and valuable actions for themselves at the locale of everyday life. It is this multifarious individual participation, and the dynamic social networks and ample learning opportunities it brings about, that we argue may generate not only challenges but also hopes, if not optimism, in our contemporary urban lives. The trivialities of everyday life in the city are capable of making changes that may not be as trivial as they seem.

Author Contributions: Conceptualization, S.C.; methodology, S.C.; investigation, S.C.; analysis, S.C. and J.L.; writing—original draft preparation, S.C.; writing—review and editing, S.C. and J.L. All authors have read and agreed to the published version of the manuscript.

Funding: This research was funded by European Research Council Consolidator Grant ChinaCreative 616882, Shenzhen Research Institute of High-Quality Development and New Structure Grant 20210017 and HITSZ Academic Staff Development Fund 20190054. 
Institutional Review Board Statement: Ethical review and approval were waived for this study, due to the fact that informed consent was obtained from all subjects involved in the study, and under the requests of informants, some data is anonymized or pseudonymized.

Informed Consent Statement: Informed consent was obtained from all subjects involved in the study.

Data Availability Statement: The data presented in this study are available on request from the corresponding author. The data are not publicly available due to the requests of some informants.

Conflicts of Interest: The authors declare no conflict of interest.

\section{References}

1. Keane, M.; Chen, Y. Entrepreneurial solutionism, characteristic cultural industries and the Chinese dream. Int. J. Cult. Policy 2017, 25, 1-13. [CrossRef]

2. Southern Metropolis Daily Makerspaces in Shenzhen Increased from Four to Two Hundred within One Year. Southern Metropolis Daily. 21 January 2016. Available online: http:/ / finance.oeeee.com/html/201601/21/362449.html (accessed on 16 August 2020).

3. Peppler, K.; Bender, S. Maker Movement Spreads Innovation One Project at a Time. Phi Delta Kappan 2013, 95, 22-27. [CrossRef]

4. Smith, A.G.; Hielscher, S.; Dickel, S.; Söderberg, J.; Van Oost, E. Grassroots Digital Fabrication and Makerspaces: Reconfiguring, Relocating and Recalibrating Innovation? SSRN Electron. J. 2013. [CrossRef]

5. Carstensen, T. Gendered Fab Labs. In Fab Lab: Of Machines, Makers and Inventors; Walter-Herrmann, J., Corinne, B., Eds.; Transcript-Verla: Bielefeld, Germany, 2014.

6. Scholz, T. (Ed.) Digital Labor: The Internet as Playground and Factory; Routledge: Abingdon, UK, 2012.

7. Fiorentino, S. Re-making urban economic geography. Start-ups, entrepreneurial support and the Makers Movement: A critical assessment of policy mobility in Rome. Geoforum 2018, 93, 116-119. [CrossRef]

8. Perng, S.-Y.; Kitchin, R.; Mac Donncha, D. Hackathons, entrepreneurial life and the making of smart cities. Geoforum 2018, 97, 189-197. [CrossRef]

9. Schrock, G.; Wolf-Powers, L. Opportunities and Risks of Localised Industrial Policy: The Case of 'Maker Entrepreneurial Ecosystems 'in the USA. Camb. J. Reg. Econ. Soc. 2019, 12, 369-384. [CrossRef]

10. Stephen, J.M. Making imaginaries: Identity, Value, and Place in the Maker Movement in Detroit and Portland. Ph.D. Thesis, Portland State University, Portland, OR, USA, 2019.

11. Silvia, L. Making Subjectivities: How China's DIY makers Remake Industrial Production, Innovation and the Self. In Proceedings of the Eleventh Chinese Internet Research Conference (CIRC11), Oxford, UK, 15 June 2013; Volume 15.

12. Lindtner, S. Hackerspaces and the Internet of Things in China: How makers are reinventing industrial production, innovation, and the self. China Inf. 2014, 28, 145-167. [CrossRef]

13. Silvia, L. Hacking with Chinese Characteristics: The Promises of the Maker Movement against China's Manufacturing Culture. Sci. Technol. Hum. Values 2015, 40, 854-879.

14. Silvia, L. Laboratory of the Precarious: Prototyping Entrepreneurial Living in Shenzhen. Women's Stud. Q. 2017, 45, 287-305.

15. Wen, W. Making in China: Is maker culture changing China's creative landscape? Int. J. Cult. Stud. 2017, 20, 343-360. [CrossRef]

16. Wang, J. The Makers Are Coming! China's Long Tail Revolution. In Handbook of Cultural and Creative Industries in China; Michael, K., Ed.; Edward Elgar Publishing: Cheltenham, UK, 2016.

17. Nesta. Made in China: Makerspaces and the Search for Mass Innovation. Available online: http://www.nesta.org.uk/ publications / made-china-makerspaces-and-search-mass-innovation (accessed on 17 September 2020).

18. Marshall, J.; Catharine, R. Making with China. Digit. Cult. Soc. 2017, 3, 127-138. [CrossRef]

19. Bolli, M. Innovators in Urban China: Makerspaces and Marginality with Impact. Urban Plan. 2020, 5, 68-77. [CrossRef]

20. Kim, C. Locating creative city policy in East Asia: Neoliberalism, developmental state and assemblage of East Asian cities. Int. J. Cult. Policy 2015, 23, 312-330. [CrossRef]

21. Harvey, D. A Brief History of Neoliberalism; Oxford University Press: Oxford, UK, 2005.

22. Comunian, R. Rethinking the Creative City: The Role of Complexity, Networks and Interactions in the Urban Creative Economy. Urban Stud. 2011, 48, 1157-1179. [CrossRef]

23. De Certeau, M. The Practice of Everyday Life; University of California Press: Berkeley, CA, USA, 1984.

24. Carlson, M. Performance: A Critical Introduction; Routledge: Abingdon, UK, 2013.

25. Khondker, H.H. Globalization and State Autonomy in Singapore. Asian J. Soc. Sci. 2008, 36, 35-56. [CrossRef]

26. Luo, Y.; Chan, R.C. Production of coworking spaces: Evidence from Shenzhen, China. Geoforum 2020, 110, 97-105. [CrossRef]

27. Deng, X. Selected Works of Deng Xiaoping; People's Publishing House: Beijing, China, 1994; Volume 3.

28. McFarlane, C. The City as a Machine for Learning. Trans. Inst. Br. Geogr. 2011, 36, 360-376. [CrossRef]

29. Smart, A. Ethnographic perspectives on the mediation of informality between people and plans in urbanising China. Urban Stud. 2018, 55, 1477-1483. [CrossRef]

30. Zhang, X. Shenzhen's GDP Exceeded 2.4 Trillion in 2018, Becoming the 5th Economy in Aggregate Terms among Asian Cities. 2019. Available online: http:/ / www.oeeee.com/html/201901/18/733930.html (accessed on 10 September 2020). 
31. Chen, X.; de'Medici, T. From a fishing village via an instant city to a secondary global city: The 'miracle' and growth pains of Shenzhen Special Economic Zone in China. In Rethinking Global Urbanism: Comparative Insights from Secondary Cities; Chen, X., Ahmed, K.K., Eds.; Routledge: Abingdon, UK, 2012; Volume 7.

32. Liu, L. Creativity, Clusters and Fine-Grain Networks: An Investigation of Culture-led Urban Regeneration in Australia and China. Ph.D. Thesis, Monash University, Melbourne, Australia, 2015.

33. Wan, G. To Build the New Engine for Mass Entrepreneurship and Innovation through the Reform Mindset. Available online: http:/ / www.chinanews.com/cj/2015/03-26/7159999.shtml (accessed on 16 August 2020).

34. Lindtner, S.; Seyram, A. Tinkering with Governance: Technopolitics and the Economization of Citizenship. In Proceedings of the ACM on Human-Computer Interaction 1(CSCW), Portland, OR, USA, 25 February-1 March 2017; pp. 1-18.

35. Riskin, C.; Zhao, R.; Li, S. China's Retreat from Equality: Income Distribution and Economic Transition; Routledge: Abingdon, UK, 2016.

36. Wang, Z. The Chinese Dream: Concept and Context. J. Chin. Political Sci. 2013, 19, 1-13. [CrossRef]

37. Gow, M. The Core Socialist Values of the Chinese Dream: Towards a Chinese integral state. Crit. Asian Stud. 2016, 49, 92-116. [CrossRef]

38. Cui, X.; Zou, L. Shenzhen to Set up Fund for Makers and Promote the Development of Maker Movement. Available online: https:/ /news.sina.cn/2015-06-20/detail-ifxefuqz1034744.d.html (accessed on 25 July 2020).

39. Xue, X. Supportive Policies for Student Entrepreneurs in Shenzhen. Available online: http://www.xuexila.com/chuangye/ zhengce/1008794.html (accessed on 10 January 2020).

40. Zhang, X. Maker Ranked First in the Top Ten Buzzwords in Chinese Newspaper in the First Half of 2015. Available online: http:/ / media.people.com.cn/n/2015/0721/c40606-27336633.html (accessed on 10 September 2020).

41. Parker, E. The Chinese Government is Investing Heavily in the Maker Movement. Available online: https://slate.com/ technology/2014/05/the-chinese-government-is-investing-heavily-in-the-maker-movement.html (accessed on 30 September 2020).

42. Dougherty, D. Free to Make: How the Maker Movement Is Changing Our Schools, Our Jobs, and Our Minds; North Atlantic Books: Berkeley, CA, USA, 2016.

43. Pang, L. Creativity and Its Discontents: China's Creative Industries and Intellectual Property Rights Offenses; Duke University Press: Durham, NC, USA, 2012.

44. Chinaventure. Ten Key Words of the Makerspaces in 2015. Annual Report. Available online: https://wenku.baidu.com/view/a5 1d54dc915f804d2a16c1d6.html (accessed on 17 July 2019).

45. Xue, Y.; Made in China: The Boom and Bust of Makerspaces. November. Available online: https://www.sixthtone.com/news/10 03171/made-in-china-the-boom-and-bust-of-makerspaces (accessed on 10 January 2020).

46. Cyrill, M. The '996' Work Culture That's Causing a Burnout in China's Tech World. Available online: https://www.china-briefing. $\mathrm{com} /$ news/996-work-culture-china-tech-sector-burnout/ (accessed on 17 September 2020).

47. Hoffman, L.M. Patriotic Professionalism in Urban China: Fostering Talent; Temple University Press: Philadelphia, PA, USA, 2010.

48. Lin, J. Be creative for the state: Creative workers in Chinese state-owned cultural enterprises. Int. J. Cult. Stud. 2019, 22, 53-69. [CrossRef]

49. Zhao, M. The Social Enterprise Emerges in China; Stanford Social Innovation Review Spring Issue: Standford, CA, USA, 2012; pp. 31-35.

50. Breaux, C. Why Making? Comput. Compos. 2017, 100, 27-35. [CrossRef] 